\title{
PEEK-biphasic bioceramic composites promote mandibular defect repair and upregulate BMP-2 expression in rabbits
}

\author{
HEDONG YU, YONGJI CHEN, MIN MAO, DONGYAN LIU, JUN AI and WEIDONG LENG \\ Department of Stomatology, Taihe Hospital, Hubei University of Medicine, Shiyan, Hubei 442000, P.R. China
}

Received July 26, 2017; Accepted December 12, 2017

DOI: $10.3892 / \mathrm{mmr} .2018 .8867$

\begin{abstract}
The present study aimed to investigate whether bone morphogenetic protein-2 (BMP-2) was involved in the repair of mandibular defects using polyether-ether-ketone biphasic bioceramic (PEEK-BBC) composites in rabbits. PEEK-BBC composites with abundant and interconnected pores were prepared by calcination and characterized by scanning electron microscope. A mandibular defect model in rabbits was established using dental grinder to produce a square hole. A total of 60 rabbits were divided into four groups: Control, sham, surgery, and PEEK. In the PEEK group, the holes were filled with the PEEK-BBC composite stents. In the surgery group, the holes were produced but not filled with the composite stents. In the sham group, only the molar grooves were exposed and grinding was not performed. Animals without any treatment served as the control group. The success rate of model establishment was $100 \%$. At 4, 8, and 16 weeks after the model was established, samples were collected from the molding sites. Bone repair was evaluated by $\mathrm{H} \& \mathrm{E}$ staining and Goldner trichrome staining. Bone structures in both control and sham groups were intact. A small number of osteocytes were observed in the surgery group. However, in the PEEK group, osteocytes were already evidently present in the composites at 4 weeks after surgery. At 8 and 16 weeks, there were large numbers of osteocytes in the pores of the composites. The mRNA and protein expression levels of BMP-2 were determined by reverse transcription-quantitative polymerase chain reaction and western blotting, respectively. The mRNA and protein expression levels of BMP-2 between the control and sham groups were similar and were continuously stable. However, following defect treatment, BMP-2 mRNA and protein expression was upregulated, which was enhanced by the PEEK-BBC composites. In conclusion, PEEK-BBC composites promoted the growth of osteocytes
\end{abstract}

Correspondence to: Professor Weidong Leng, Department of Stomatology, Taihe Hospital, Hubei University of Medicine, 30 Renmin South Road, Shiyan, Hubei 442000, P.R. China

E-mail: lengweidong68@163.com

Key words: polyether-ether-ketone, bioceramic, bone repair, mandibular defect, bone morphogenetic protein-2 and repaired mandibular defects in rabbits, potentially via the upregulation of BMP-2 expression.

\section{Introduction}

Mandibular defects are common and can be cause by various traumas. Mandibular regeneration and reconstruction are continuously difficult problems in clinical treatment. At present, the most common bone repair procedures in the clinic are transplantation with autogenous or allogeneic bone, and filling with artificial biomaterials. However, there are numerous of disadvantages of autogenous or allogeneic bone transplantation, including difficult obtainment of suitable bone, insufficient supply, dissatisfactory matching, susceptibility to infection, rejection reaction and increased pain $(1,2)$. Therefore, bone transplantation creates great difficulties in clinical treatments $(3,4)$. In order to improve bone tissue repair, bone tissue engineering has become a popular method. Stent composites provide a novel strategy for bone repair in the wake of the continuous research and development of bone tissue engineering (5). Currently, it has been reported that artificial biomaterials have significant effects on bone repair, however there are also numerous deficiencies (6). Therefore, it is important to increase the effectiveness of the filling material for the repair of defective bone.

As special engineering plastic, polyether-ether-ketone (PEEK) is a type of hypocrystalline organic polymer with preferable and stable biocompatibility, biodegradability, thermoplasticity, high temperature resistance, corrosion resistance and wear resistance (7-9). Additionally, it also has the advantages of radiation transparency and nuclear magnetic resonance scanning without the generation of artifacts (10), thus, it is used as a substitute for spinal implants. This allows the extensive application of PEEK in the medical field and it has become an important orthopedic implant (11). PEEK had been widely accepted and employed as a substitute for prosthesis and metal implants, including lumbar fusion cage and cardiac valves, and has produced satisfactory results $(12,13)$. In addition, a variety of novel PEEK composites have been successfully developed and applied to treat oral bone defects. Bioceramic material has been extensively used in oral clinics due to its superior biological characteristics (14). Composites produced from the combination of PEEK and biphasic bioceramic material are more similar to endogenous biological structures, which will enhance the repair function of filling materials on bone defects. However, currently, the molecular 
mechanisms involved in the repair function of PEEK-biphasic bioceramic $(\mathrm{BBC})$ composites on bone defect require further investigation.

Bone morphogenetic protein-2 (BMP-2) is a member of the transforming growth factor- $\beta$ superfamily. Numerous studies have confirmed that BMP-2 can induce undifferentiated mesenchymal cells to differentiate into bone cells, improving the activity and proliferation of bone cells at bone defect sites, and sequentially promoting the bone reconstruction and regeneration (15). BMP-2 is one of the strongest factors with osteogenic capability in the BMP family (16); BMP-2 may promote bone repair directly or indirectly.

Therefore, the present study aimed to reveal whether BMP-2 is involved in the bone repair process of PEEK-BBC composites by investigating the alterations in BMP-2 expression in the repair effects of PEEK-BBC composites on mandibular defects in a rabbit model.

\section{Materials and methods}

Materials. Bovine serum albumin (BSA) and Goldner trichrome staining kit were obtained from Beijing Solarbio Science \& Technology Co., Ltd. (Beijing, China). A hematoxylin and eosin (H\&E) staining kit, rabbit anti- $\beta$-actin antibody (cat. no. TA-09) and horseradish peroxidase (HRP)-labeled goat anti-rabbit immunoglobulin G (IgG; $\mathrm{H}+\mathrm{L}$; cat. no. ZB-2301) were purchased from OriGene Technologies, Inc. (Beijing, China). Rabbit anti-BMP-2 antibody was obtained from Abcam (Cambridge, MA, USA; cat. no. ab6285). HiFiScript cDNA synthesis kit was from Jiangsu Kang for the Century Biological Technology Co., Ltd. (Beijing, China). Radioimmunoprecipitation assay (RIPA) lysis buffer was from Applygen Technologies, Inc. (Beijing, China). The RNA extraction kit was purchased from Tiangen Biotech Co., Ltd. (Beijing, China).

Preparation of PEEK-BBC composites. Following the obtainment of ethical approval from the Institutional Ethical Committee of Hubei University of Medicine (Shiyan, China) and written informed consent from ten patients, twenty human tooth tissues were collected and pretreated to remove the peripheral tissues. Subsequently, the tooth tissues were immersed in 5\% sodium hypochlorite solution for $24 \mathrm{~h}$. Ultrasonic washing was performed three times for $1 \mathrm{~h}$ each time. Following dehydration in absolute ethanol for $1 \mathrm{~h}$, first stage calcination was initiated by calcining for $1 \mathrm{~h}$ at $800^{\circ} \mathrm{C}$. The teeth were immersed in $0.1 \mathrm{~mol} / 1\left(\mathrm{NH}_{4}\right)_{2} \mathrm{HPO}_{4}$ for $24 \mathrm{~h}$ following natural cooling, and were then dried and calcined for $1 \mathrm{~h}$ at $800^{\circ} \mathrm{C}$ again. The temperature was elevated to $1,150^{\circ} \mathrm{C}$ to calcine for another $2 \mathrm{~h}$ followed by natural cooling. The teeth were ground and sieved to prepare bioceramic powder.

Organic foam materials were immersed in $10 \% \mathrm{NaOH}$ and heated to $60^{\circ} \mathrm{C}$ for $15 \mathrm{~min}$, washed with pure water and dried. Polyvinyl butyral $(15 \mathrm{ml})$ and tooth powder $(50 \mathrm{~g})$ were dissolved in $300 \mathrm{ml}$ of absolute ethanol by continuous stirring for $2 \mathrm{~h}$. Subsequently, the sponge was immersed in the mixture and baked at $80^{\circ} \mathrm{C}$ for 1 day. The composites were finally calcined at $1,250^{\circ} \mathrm{C}$ for $3 \mathrm{~h}$. Following natural cooling, the composites were characterized under a Schottky field emission scanning electron microscope (Olympus Corporation, Tokyo, Japan).
The elemental components of the composites were determined by inductively coupled plasma-atomic emission spectrometry (ICP-AES) based on elemental analysis.

Animals. A total of 60 New Zealand white rabbits (2-3 months old, $2-2.5 \mathrm{~kg}$ ) were obtained from experimental animal center of Medical College, Nanchang University (Nanchang, China). The animals were fed in a room with $22-25^{\circ} \mathrm{C}, 40-60 \%$ humidity, and natural light/dark cycle; prior to fasting food intake is free food and water are changes once a day. The animals had free access to food and water and were fasted $12 \mathrm{~h}$ prior to experiments. The study protocol was approved by the Institutional Animal Care and Use Committee of Hubei University of Medicine and was in accordance with the guidelines established by the Chinese Council of Animal Care (17).

Establishment of mandibular defect model. A total of 60 rabbits were divided into four groups $(n=15)$ : Control, sham, surgery and PEEK. Each rabbit was fixed on an operating table and $30 \mathrm{mg} / \mathrm{kg}$ pentobarbital sodium $(1 \mathrm{ml} / \mathrm{kg})$ was injected into the ear vein. The skin was incised to expose the groove part of molars. The bone was ground with a dental grinder to produce a square hole with $12 \times 10 \times 2 \mathrm{~mm}$ (length $\mathrm{x}$ width $\mathrm{x}$ depth). All the groups were modeled on the same side. In the PEEK group, the holes were filled with the PEEK-BBC composite stents. In the surgery group, the holes were produced but not filled with the composite stents. In the sham group, only the molar grooves were exposed and defect treatment was not performed. Animals without any treatment served as the control. Following the operation, 800,000 units of penicillin were injected for 3 consecutive days to prevent infection. Rabbits in all groups were euthanized at 4,8 and 16 weeks postoperation $(n=5$ per group) and the samples in the molding sites were collected.

$H \& E$ staining. Mandibular samples were fixed in $10 \%$ neutral formaldehyde buffer at room temperature for $1 \mathrm{~h}$ and decalcified in 5\% hydrochloric acid for 3-4 days. Following paraffin embedding, the samples were cut into slices $(4-\mu \mathrm{m})$. The slices were incubated in hematoxylin alcoholic solution $(6 \%)$ for $2 \mathrm{~min}$ at room temperature. Then, they were immersed in acid water and ammonia water for color separation for several sec, respectively. Following washing with running water for $1 \mathrm{~h}$, the slices were immersed in distilled water for a moment. The sections were then dehydrated in 70 and $90 \%$ ethanol for $10 \mathrm{~min}$ each. Subsequently, the slices were incubated in eosin solution $(0.5 \%)$ for $2-3 \mathrm{~min}$ at room temperature and dehydrated in absolute ethanol; sections were transparentized with $100 \%$ xylene for $5 \mathrm{~min}$ at room temperature and mounted with Canada balsam. Finally, the sections were observed under a light microscope (CKX41; Olympus Corporation).

Goldner trichrome staining. Following xylene deparaffination $(100 \%)$ for $5 \mathrm{~min}$ at room temperature, the paraffin sections were washed with ethanol $(80,95$, and $100 \%$; each $5 \mathrm{~min})$ at room temperature and immersed in water. Then the sections were incubated in Weigert iron hematoxylin solution for $25 \mathrm{~min}$ at room temperature. Prior to immersion in acid alcohol solution (1\%) for $3 \mathrm{sec}$ at room temperature for differentiation, the sections were washed with running water for $1 \mathrm{~min}$. After washing with running water and distilled water, sections were stained in acid 
Ponceau solution $(0.1 \%)$ for $5 \mathrm{~min}$ at room temperature. In the aforementioned process, a weak acid working solution was prepared according to the 4:1 ratio of distilled water to weak acid solution and the wash was conducted with the weak acid working solution. Sections were stained in Orange G solution, till Ponceau solution (0.1\%) for 3-5 min at room temperature followed by a wash with the weak acid working solution ( $\mathrm{pH}$ 6.5) for $10 \mathrm{sec}$ at room temperature. Immediately, the sections were stained in brilliant green solution for $5 \mathrm{~min}$ at room temperature and washed three times with the weak acid working solution ( $\mathrm{pH}$ 6.5) for $15 \mathrm{sec}$ at room temperature. Following washing with distilled water, the slices were blotted up or dried in the air and then rapidly dehydrated in absolute ethanol, and mounted with neutral balsam. Finally, the sections were observed under a light microscope (CKX41; Olympus Corporation).

Reverse transcription-quantitative polymerase chain reaction $(R T-q P C R)$. RNA was extracted from the samples and reverse transcribed into cDNA according to the protocols of the HiFiScript cDNA synthesis kit. The product was stored at $-80^{\circ} \mathrm{C}$. The RT system $(20 \mu \mathrm{l})$ comprised of: dNTP mix $(4 \mu \mathrm{l})$, primer mix $(2 \mu \mathrm{l})$, RNA template $(7 \mu \mathrm{l}), 5 \mathrm{X}$ RT buffer $(4 \mu \mathrm{l})$, dithiothreitol (DTT; $2 \mu \mathrm{l}$ ), and HiFiScript (1 $\mu \mathrm{l})$. Total RNA in diethylpyrocarbonate water was mixed by vortexing and then transiently centrifuged at $4^{\circ} \mathrm{C}$ and $10,000 \mathrm{x}$ g for $15 \mathrm{~min}$ to collect the solution on the tube wall into the bottom of the tube; dNTP mix, primer mix, and RNA template were then added. Following incubation at $70^{\circ} \mathrm{C}$ for $10 \mathrm{~min}$, the mixture was rapidly placed in ice bath for $2 \mathrm{~min}$. Subsequently 5 X RT buffer, DTT and HiFiScript were added and the final mixture was incubated at $50^{\circ} \mathrm{C}$ for $15 \mathrm{~min}$ and at $85^{\circ} \mathrm{C}$ for $5 \mathrm{~min}$. The qPCR reaction system $(25 \mu \mathrm{l})$ constituted: RNase free double distilled water $(9.5 \mu \mathrm{l})$, cDNA/DNA $(1 \mu \mathrm{l})$, forward primer (1 $\mu \mathrm{l})$, reverse primer $(1 \mu \mathrm{l})$, and $2 \mathrm{X}$ UltraSYBR Mixture (12.5 $\mu$ l, CW0957; ComWinBIO Co., Ltd., Beijing, China). The sequences of primers are presented in Table I. The qPCR parameters were set as follows: Predegeneration for $3 \mathrm{~min}$ at $95^{\circ} \mathrm{C}$, denaturation for $10 \mathrm{sec}$ at $95^{\circ} \mathrm{C}$, annealing for $30 \mathrm{sec}$ at $50-55^{\circ} \mathrm{C}$, elongation for $30 \mathrm{sec}$ at $72^{\circ} \mathrm{C}, 40$ cycles, and final elongation for $10 \mathrm{~min}$ at $72^{\circ} \mathrm{C}$. The amplification products were separated via agarose gel electrophoresis. $\beta$-actin served as internal control. Relative expression levels of genes were calculated by using the $2^{-\Delta \Delta \mathrm{Cq}}$ method (18).

Western blotting. The samples were removed from liquid nitrogen storage. The areas required were sawed and ground into fine powder. The powder was added to RIPA buffer containing phenylmethanesulfonyl fluoride. The lysate were centrifuged at $10,000 \mathrm{xg}$ at $4^{\circ} \mathrm{C}$ for $10 \mathrm{~min}$. The supernatant was collected and $5 \mathrm{X}$ loading buffer was added. The mixture was boiled with boiling water for $5 \mathrm{~min}$ and then centrifuged again at $10,000 \mathrm{x} \mathrm{g}$ at $4^{\circ} \mathrm{C}$ for $3 \mathrm{~min}$ and the supernatant was collected. Protein concentration was determined by bicinchoninic acid kit. SDS-PAGE gels were prepared (15\% separation gel for BMP-2, $15 \%$ separation gel for $\beta$-actin). Protein samples $(10 \mu \mathrm{g})$ and a marker were loaded, and electrophoresis was initiated. The voltages were set as 60 and $80 \mathrm{~V}$ to compress and separate proteins, respectively. Transfer buffer was prepared and precooled. A polyvinylidene fluoride membrane was tailored in accordance with the position of strips and
Table I. Primers for reverse transcription-quantitative polymerase chain reaction.

Gene $\quad$ Primer $\left(5^{\prime}-3^{\prime}\right)$

$\begin{array}{ll}\begin{array}{ll}\text { Bone } \\ \text { morphogenetic } \\ \text { protein-2 }\end{array} & \text { Forward: CGTGAGGATTAGCAGGTCT } \\ \beta \text {-actin } & \begin{array}{l}\text { Forward: ATCGTCCACCGTAAATGC } \\ \end{array} \\ & \text { Reverse: TGAAGTGGTAGTCGGGTG }\end{array}$

then activated in methanol for $15 \mathrm{sec}$. Sizeable gel containing target bands was cut to prepare a 'sandwich' (sponge-filter paper-gel-membrane-filter paper-sponge). According to the voltage and molecular weight, duration of transfer was controlled to $\sim 1.5 \mathrm{~h}$. The membrane was immersed in $5 \%$ BSA overnight at $4^{\circ} \mathrm{C}$ for blocking. Following washing, the membrane was incubated in primary antibody buffer (rabbit anti- $\beta$-actin antibody, 1:2,000; rabbit anti-BMP-2 antibody, 1:1,000) for $3 \mathrm{~h}$ at room temperature. Following three washes for $10 \mathrm{~min}$ each time, the membrane was incubated in secondary antibody buffer [HRP-labeled goat anti-rabbit IgG $(\mathrm{H}+\mathrm{L}), 1: 2,000]$ for $2 \mathrm{~h}$ at room temperature, and washed three times for $10 \mathrm{~min}$. A luminescent solution (SuperSignal ${ }^{\circledR}$ west pico chemiluminescent substrate, RJ239676; Thermo Fisher Scientific, Inc., Waltham, MA, USA) was applied onto the membrane. Finally, the membrane and the gray values of the bands were analyzed by using a gel imaging system (ChemiDoc ${ }^{\mathrm{TM}}$ XRS; Bio-Rad Laboratories, Inc., Hercules, CA, USA) and a Quantity One software (v4.6.2; Bio-Rad Laboratories, Inc.).

Statistical analysis. A total of three repeats were performed and data was presented as the mean \pm standard deviation. Statistical analysis was performed with one way analysis of variance followed by Tukey's post hoc test using SPSS software (version 17.0; SPSS, Inc., Chicago, IL, USA). P<0.05 was considered to indicate a significantly significant difference.

\section{Results}

Preparation and characterization of PEEK-BBC composites. The microstructure of the PEEK-BBC composites evaluated by scanning electron microscope is presented in Fig. 1. There were abundant rounded or sub-rounded pores interconnected within the PEEK-BBC composites. It was suggested that the PEEK-BBC composites are porous matrixes, which may be favorable for the adhesion and growth of cells.

The elemental components of PEEK-BBC composites determined by ICP-AES are presented in Table II. The analysis showed that the composites were $40.5 \%$ calcium and $19.8 \%$ phosphorus. The atomic ratio of calcium to phosphorus was 1.73. In addition, the presence of magnesium, zinc, and potassium was detected. The elemental analysis was performed to detect major elements and the remaining elements may of other microelements that have not been determined yet.

Establishment of the mandibular defect model. By using a dental grinder, relatively large and deep defect holes were 

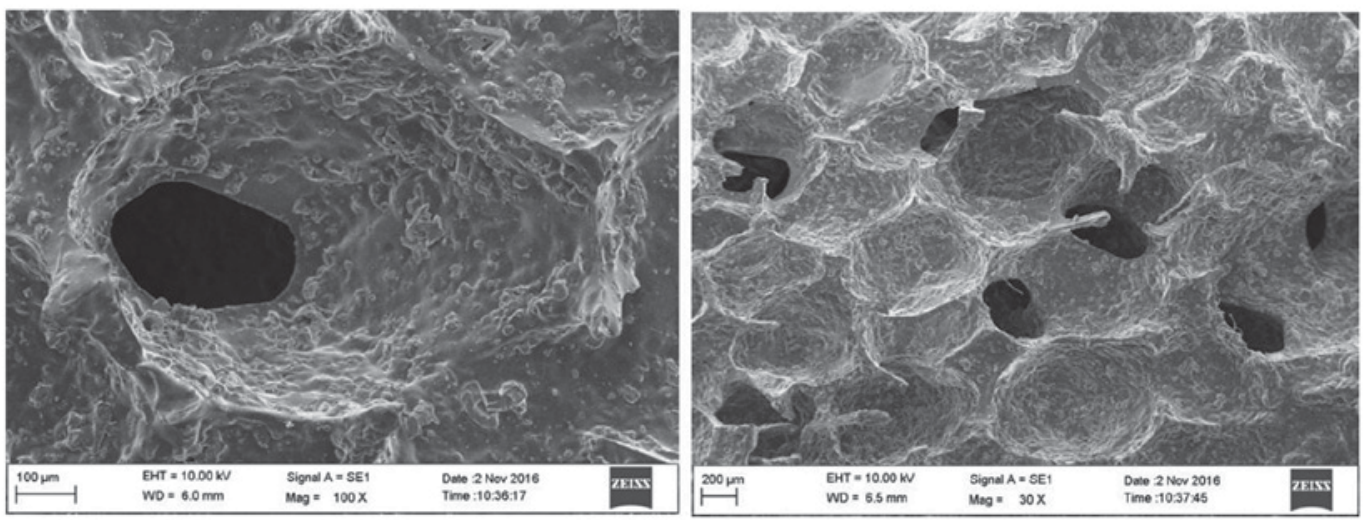

Figure 1. Microstructure of the PEEK-BBC composites evaluated by scanning electron microscope. There are abundant and interconnected rounded or sub-rounded pores in the PEEK-BBC composites. PEEK-BBC, polyether-ether-ketone biphasic bioceramic; EHT, extra high tension; WD, working distance.

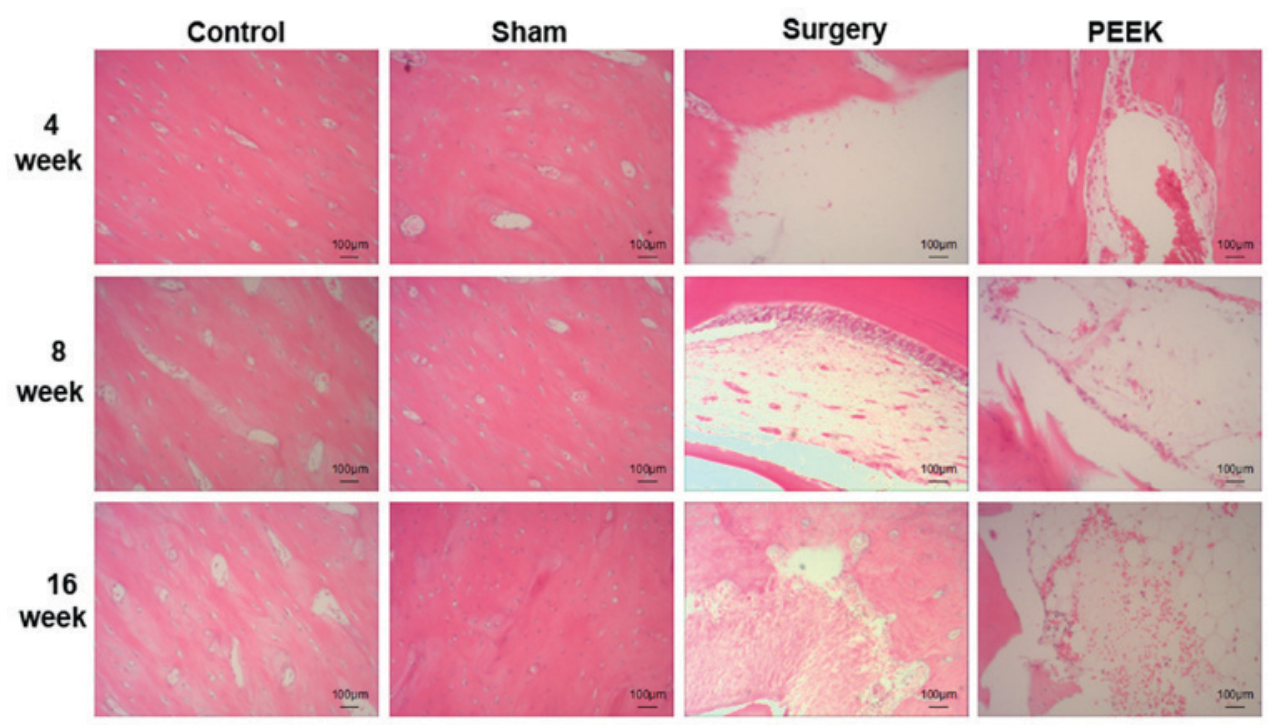

Figure 2. Pathological results of the mandibular tissues among the control, sham, surgery, and PEEK groups at 4,8 and 16 weeks postoperation, which were assessed by hematoxylin and eosin staining (magnification, x100). PEEK, polyether-ether-ketone.

produced. The success rate of the model establishment was $100 \%$ with no mortalities. All rabbits lived well with appropriate wound healing and did not exhibit any complications, such as inflammatory reaction.

Pathological characterization by $H \& E$ staining. Pathological results of the mandibular tissues among the four groups assessed by $H \& E$ staining were revealed in Fig. 2. At all time intervals, bone structures were intact in the control and sham groups. In the bone defect positions in the surgery group, few markedly positive alterations were observed, such as growth of very few cells at 4 weeks; however, the number of osteocytes was did not markedly increase at 16 weeks. In the PEEK group, numerous osteocytes formed within the pores of the PEEK-BBC composites at 4 weeks, and were widely distributed in the composites at 8 and 16 weeks.

Pathological characterization by Goldner trichrome staining. Fig. 3 demonstrates the pathology of the mandibular tissues among the four groups following Goldner trichrome staining. The mineralized bone, osteoid and cartilage were stained green,
Table II. Elemental analysis of polyether-ether-ketone biphasic bioceramic composites.

\begin{tabular}{llllll}
\hline & \multicolumn{5}{c}{ Elements } \\
\cline { 2 - 6 } $\begin{array}{l}\text { Sample } \\
\text { number }\end{array}$ & $\mathrm{P}(\%)$ & $\mathrm{Ca}(\%)$ & $\mathrm{Mg}(\%)$ & $\mathrm{Zn}(\%)$ & $\mathrm{K}(\%)$ \\
\hline 1 & 17.4 & 42.5 & 7.2 & 5.9 & 3.0 \\
2 & 19.4 & 38.6 & 5.7 & 6.1 & 2.9 \\
3 & 20.5 & 39.8 & 5.9 & 5.4 & 2.8 \\
4 & 19.9 & 41.3 & 6.9 & 5.2 & 3.8 \\
5 & 18.4 & 40.6 & 6.5 & 5.8 & 3.7 \\
Mean & 19.8 & 40.5 & 6.4 & 5.7 & 3.2 \\
\hline
\end{tabular}

orange-red and purple, respectively. Additionally, the results of Goldner trichrome staining verified those of H\&E staining. Intact bone structures in both control and sham groups were observed at all time intervals. Bone defect status in the surgery group did not markedly alter at 4 weeks due to the formation of 

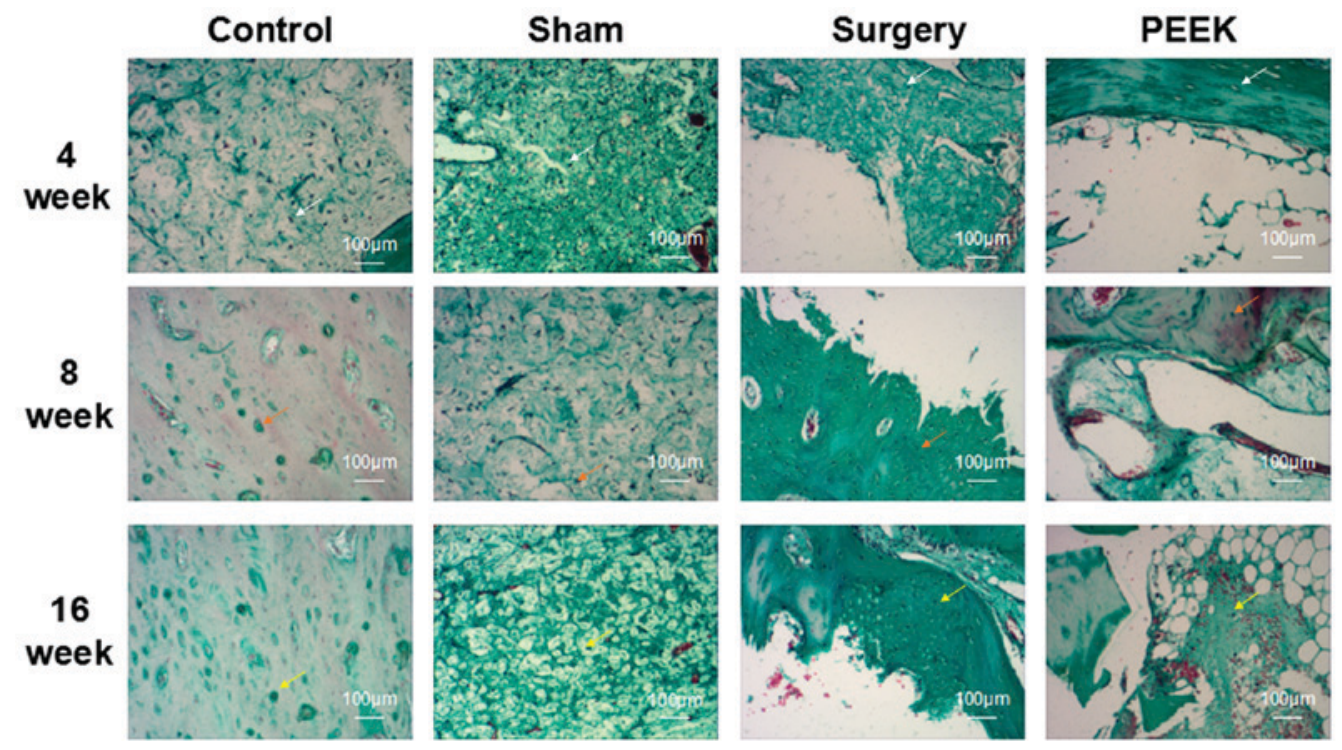

Figure 3. Pathology of the mandibular tissues among the control, sham, surgery and PEEK groups at 4, 8 and 16 weeks postoperation demonstrated by Goldner trichrome staining (magnification, x100). The mineralized bone, osteoid, and cartilage were stained as white, orange and yellow, respectively. Arrows indicate mineralized bone, osteoid and cartilage. PEEK, polyether-ether-ketone.

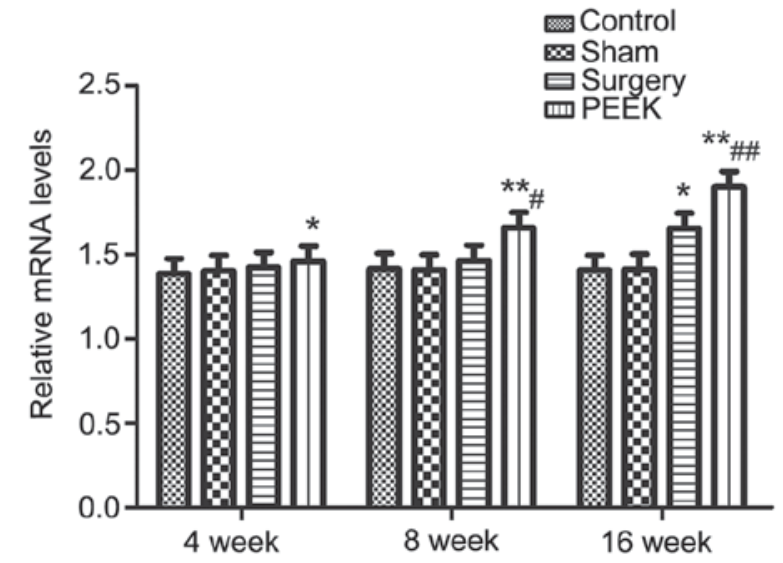

Figure 4. mRNA expression levels of bone morphogenetic protein-2 in the mandibular tissues among the control, sham, surgery and PEEK groups at various time intervals ( 4,8 and 16 weeks), which were determined by reverse transcription-quantitative polymerase chain reaction with $\beta$-actin as the internal control. ${ }^{*} \mathrm{P}<0.05,{ }^{* *} \mathrm{P}<0.01$ vs. control group; ${ }^{\#} \mathrm{P}<0.05,{ }^{\# \prime} \mathrm{P}<0.05$ vs. surgery group. PEEK, polyether-ether-ketone.

a minute quantity of cells. At 16 weeks, some osteocytes were observed; however, the cell number remained low. By contrast, in the PEEK group, osteocytes were evidently present in the PEEK-BBC composites at 4 weeks. At the subsequent 8 and 16 weeks, there were large numbers of osteocytes in the pores of the composites.

BMP-2 mRNA expression levels determined by RT-qPCR. mRNA expression levels of BMP-2 in the mandibular tissues among the various groups at different time intervals were determined by RT-qPCR. The results are presented in Fig. 4 and $\beta$-actin served as the internal control. The mRNA expression levels of BMP-2 between the control and sham groups were similar and they were stable without any difference among the three time intervals. Until 16 weeks, the mRNA expression levels of BMP-2 in the surgery group was significantly elevated
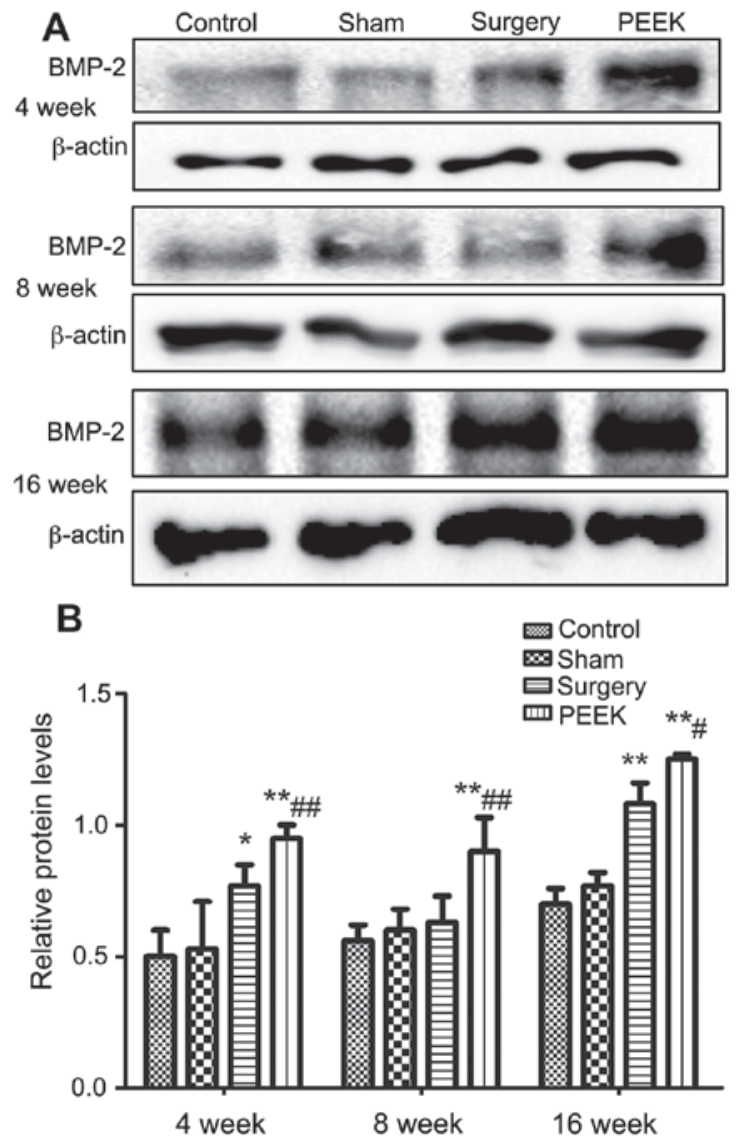

Figure 5. Protein expression levels of BMP-2 in the mandibular tissues among the control, sham, surgery and PEEK groups at various time intervals $(4,8$ and 16 weeks), which were evaluated by (A) western blotting and (B) densitometry analysis with $\beta$-actin as the internal control. ${ }^{*} \mathrm{P}<0.05,{ }^{* * *} \mathrm{P}<0.01$ vs control group; ${ }^{\#} \mathrm{P}<0.05,{ }^{\# \#} \mathrm{P}<0.05$ vs. surgery group. BMP-2, bone morphogenetic protein-2; PEEK, polyether-ether-ketone.

compared with in the control group $(\mathrm{P}<0.05)$. However, at 4 , 8 and 16 weeks, the mRNA expression levels of BMP-2 in the 
PEEK group were significantly increased as compared with in the control group $(\mathrm{P}<0.05, \mathrm{P}<0.01$ and $\mathrm{P}<0.01$, respectively). As for the difference between the surgery and PEEK groups, significantly higher levels of BMP-2 were detected in the PEEK group at 8 and 16 weeks compared with in the surgery group $(\mathrm{P}<0.05$ and $\mathrm{P}<0.01$, respectively).

BMP-2 protein expression levels evaluated by western blotting. The protein expression levels of BMP-2 in the mandibular tissues among diverse groups at different time intervals was evaluated by western blotting. $\beta$-actin served as the internal control for analysis (Fig. 5). Variation tendency of BMP-2 protein expression levels were similar to those of corresponding mRNA levels. At 4 and 8 weeks, compared with the other three groups, markedly darker bands were observed in the PEEK group. The expression of BMP-2 protein was significantly upregulated by the PEEK-BBC composites treatment $(\mathrm{P}<0.01)$ compared with the surgery group at 8 weeks. The longest duration (16 weeks), revealed a slight enhancement of BMP-2 protein expression of the control and sham groups compared with the earlier time points. However, the BMP-2 band in the surgery group was markedly darker, revealing higher expression of BMP-2 protein compared with in the control group. Additionally, BMP-2 protein expression levels were further upregulated in the PEEK group compared with the surgery group $(\mathrm{P}<0.05)$. Consistently, the expression of BMP-2 protein was similar between the control and sham groups.

\section{Discussion}

The use of artificial biomaterials, such as composites, have been reported to avoid the disadvantages of using traditional autogenous or allograft bone to repair bone defects. Additionally, artificial biomaterials are biocompatible; they are able to promote cell proliferation and differentiation, and facilitate bone tissue repair. Numerous studies have reported that tissue engineering of bone using composites may be a novel strategy for bone repair and reconstruction $(3,19,20)$.

Bioceramic material is one of the most frequently used materials in treating oral bone defects. It possesses corresponding biological functions, commendable mechanical properties and biocompatibility, corrosion resistance and wear resistance. These characteristics make the potential used of bioceramic materials very extensive (21-24). It has been reported that numerous factors including, pore size, structure distribution and morphology, influence the biological function of biomaterials (25-27). In the present study, PEEK/BBC composites were prepared via calcination. Its major components were $\beta$-tricalcium phosphate and hydroxylapatite, and the major elements were calcium and phosphorus. Therefore, the chemical composition was similar to that of human skeleton. Furthermore, scanning electron microscopy revealed the network structure of these composites with interconnected pores. This porous structure of composites may provide an ideal environment for the growth and repair of bone tissues. The degradation of the calcium component in the composites may also participate in human metabolism, promoting bone repair and reconstruction (28).

Mandibular defects in rabbits were produced using a dental grinder. Following various treatments, such as composite implanting, pathological evaluations were conducted using $\mathrm{H} \& \mathrm{E}$ and Goldner trichrome staining, which demonstrated the osteogenesis-promoting ability of PEEK-BBC composites. It was demonstrated that PEEK-BBC composites were biocompatible and able to effectively promote the growth and differentiation of osteocytes, and consequently repair the defective bone tissues.

Bioactive factors have an important role in the process of bone reconstruction. BMP has been verified to promote the formation of bone tissue (29). BMP-2 is reported to promote cell proliferation and differentiation, improve cell viability and specifically induce osteoblast formation; BMP-2 may exhibit the greatest effect on bone repair among $>40$ types of BMP. Wang et al (30) revealed that one of the characteristics of BMP-2 was bone induction; BMP-2 was able to induce and accelerate the differentiation of bone marrow stem cells into osteocytes. In the present study, the mRNA and protein expression levels of BMP-2 were investigated by RT-qPCR and western blotting, respectively. Within the groups with bone defect, BMP-2 expression was upregulated. The results of the present study indicated that that when bone was damaged, the tissues may produce BMP-2 to induce and promote bone repair. Furthermore, the upregulation of the BMP-2 expression was further enhanced by implantation of the PEEK-BBC composites, suggesting that PEEK-BBC composites efficiently elevated the expression of BMP-2 at the mRNA and protein levels to promote bone reconstruction.

In conclusion, PEEK-BBC composites with interconnected porous structure and biocompatibility were prepared in the present study. These composites promoted the growth of osteocytes and repaired mandibular defects in rabbits and upregulating the expression of BMP-2. BMP-2 is reportedly involved in the bone repair process of PEEK-BBC composites. These findings may provide a novel strategy for drug development and clinical treatment of mandibular defects.

\section{Acknowledgements}

Not applicable.

\section{Funding}

The present study was supported by the National Natural Science Foundation of China (grant nos. 51541202 and 81671831).

\section{Availability of data and materials}

The analyzed data sets generated during the study are available from the corresponding author on reasonable request.

\section{Authors' contributions}

HY and WL designed study and wrote paper. YC, MM, DL and JA collected and analyzed data. All authors performed the study.

\section{Ethics approval and consent to participate}

The study protocol was approved by the Institutional Animal Care and Use Committee of Hubei University of Medicine 
and was in accordance with the guidelines established by the Chinese Council of Animal Care (17).

\section{Consent for publication}

Not applicable.

\section{Competing interests}

The authors declare they have no competing interests.

\section{References}

1. Crane GM, Ishaug SL and Mikos AG: Bone tissue engineering. Nat Med 1: 1322-1324, 1995.

2. Rozen N, Lewinson D, Bick T, Meretyk S and Soudry M: Role of bone regeneration and turnover modulators in control of fracture. Crit Rev Eukaryot Gene Expr 17: 197-213, 2007.

3. WangZ,Li M,YuB, CaoL, Yang Q and Su J: Nanocalcium-deficient hydroxyapatite-poly (e-caprolactone)-polyethylene glycol-poly (e-caprolactone) composite scaffolds. Int J Nanomedicine 7 : 3123-3131, 2012.

4. Levengood SK, Poellmann MJ, Clark SG, Ingram DA, Yoder MC and Johnson AJ: Human endothelial colony forming cells undergo vasculogenesis within biphasic calcium phosphate bone tissue engineering constructs. Acta Biomater 7: 4222-4228, 2011

5. Takahashi Y, Yamamoto M and Tabata Y: Enhanced osteoinduction by controlled release of bone morphogenetic protein-2 from biodegradable sponge composed of gelatin and beta-tricalcium phosphate. Biomaterials 26: 4856-4865, 2005.

6. Jazayeri HE, Tahriri M, Razavi M, Khoshroo K, Fahimipour F, Dashtimoghadam E, Almeida L and Tayebi L: A current overview of materials and strategies for potential use in maxillofacial tissue regeneration. Mater Sci Eng C Mater Biol Appl 70: 913-929, 2017.

7. Lee JH, Jang HL, Lee KM, Baek HR, Jin K, Hong KS, Noh JH and Lee HK: In vitro and in vivo evaluation of the bioactivity of hydroxyapatite-coated polyetheretherketone biocomposites created by cold spray technology. Acta Biomater 9: 6177-6187, 2013.

8. Salerno S, Piscioneri A, Laera S, Morelli S, Favia P, Bader A, Drioli $\mathrm{E}$ and De Bartolo L: Improved functions of human hepatocytes on NH3 plasma-grafted PEEK-WC-PU membranes. Biomaterials 30: 4348-4356, 2009.

9. Dennes TJ and Schwartz J: A nanoscale adhesion layer to promote cell attachment on PEEK. J Am Chem Soc 131: 3456-3457, 2009.

10. Ying Y: The study of the MRI artifacts caused by two alloys of porcelain-fused-to-metal crown. Chin J Dent Mater Dev 19: 72-74, 2010 (In Chinese).

11. Deng C, Liu D, Liu J and Liu X: Advance in polyetheretherketone (PEEK) and its composite material for orthopaedic implants. Biomed Eng Clin Med 13: 473-476, 2009 (In Chinese).

12. Kurtz SM and Devine JN: PEEK biomaterials in trauma, orthopedic, and spinal implants. Biomaterials 28: 4845-4869, 2007.

13. Pace N, Marinelli M and Spurio S: Technical and histologic analysis of a retrieved carbon fiber-reinforced poly-ether-ether-ketone composite alumina-bearing liner 28 months after implantation. J Arthroplasty 23: 151-155, 2008.
14. Converse GL, Conrad TL, Merrill $\mathrm{CH}$ and Roeder RK: Hydroxyapatite whisker-reinforced polyetherketoneketone bone ingrowth scaffolds. Acta Boimater 6: 856-863, 2010.

15. Lü K, Zeng D, Zhang Y, Xia L, Xu L, Kaplan DL, Jiang X and Zhang F: BMP-2 gene modified canine bMSCs promote ectopic bone formation mediated by a nonviral PEI derivative. Ann Biomed Eng 39: 1829-1839, 2011.

16. Seol YJ, Kim KH, Park YJ, Lee YM, Ku Y, Rhyu IC, Lee SJ, Han SB and Chung CP: Osteogenic effects of bone-morphogenetic-protein-2 plasmid gene transfer. Biotechnol Appl Biochem 49: 85-96, 2008.

17. General Administration of Quality Supervision, Inspection and Quarantine of China: Laboratory animal-Guideline of welfare ethical review (Draft for approval). Mar 18, 2017 (In Chinese).

18. Livak KJ and Schmittgen TD: Analysis of relative gene expression data using real-time quantitative PCR and the 2(-Delta Delta C(T)) method. Methods 25: 402-408, 2001.

19. Liao F, Chen Y,LiZ, Wang Y, Shi B, Gong Z and Cheng X: A novel bioactive three-dimensional beta-tricalcium phosphate/chitosan scaffold for periodontal tissue engineering. J Mater Sci Mater Med 21: 489-496, 2010.

20. Yu G and Fan Y: Preparation of poly(D,L-lactic acid) scaffolds using alginate particles. J Biomater Sci Polym Ed 19: 87-98, 2008.

21. Chen G, Li W, Yu X and Sun K: Study of the cohesion of TTCP/DCPA phosphate cement through evolution of cohesion time and remaining percentage. J Mater Sci 44: 828, 2009.

22. Sayer M, Stratilatov AD, Reid J, Calderin L, Stott MJ, Yin X, MacKenzie M, Smith TJ, Hendry JA and Langstaff SD: Structure and composition of silicon-stabilized tricalcium phosphate. Biomaterials 24: 369-382, 2013.

23. Reid JW, Pietak AM, Sayer M, Dunfield D and Smith TJ: Phase formation and evolution in the silicon substituted tricalcium phosphate/apatite system. Biomaterials 26: 2887-2897, 2005.

24. Jang JH, Castano O and Kim HW: Electrospun materials as potential platforms for bone tissue engineering. Adv Drug Deliv Rev 61: 1065-1083, 2009.

25. Ishikawa K: Bone substitute fabrication based on dissolution-precipitation reactions. Materials 3: 1138-1155, 2010.

26. Becker A, Epple M, Müller KM and Schmitz I: A comparative study of clinically well-characterized human atherosclerotic plaques with histological, chemical, and ultrastructural methods. J Inorg Biochem 98: 2032-2038, 2004.

27. Dorozhkin SV: Amorphous calcium (ortho)phosphates. Acta Biomater 6: 4457-4475, 2010.

28. Bonner M, Ward IM, McGregor W, Tanner KE and Bonfield W: Hydroxyapatite/polypropylene composite: A novel bone substitute material. J Mater Sci Lett 20: pp2049-2051, 2001.

29. Dean DB, Watson JT, Moed BR and Zhang Z: Role of bone morphogenetic proteins and their antagonists in healing of bone fracture. Front Biosci (Landmark Ed) 14: 2878-2888, 2009.

30. Wang EA, Israel DI, Kelly S and Luxenberg DP: Bone morphogenetic protein-2 causes commitment and differentiation in C3H10T1/2 and 3T3 cells. Growth Factors 9: 57-71, 1993.

This work is licensed under a Creative Commons Attribution-NonCommercial-NoDerivatives 4.0 International (CC BY-NC-ND 4.0) License. 